\title{
Música e guerra: impactos da Primeira Guerra Mundial no cenário musical carioca
}

\author{
Music and War: First World War Impacts \\ in the Musical Scene of Rio de Janeiro
}

Luciana Pessanha Fagundes*

\section{Resumo}

Este artigo tem como objetivo abordar os impactos culturais da Primeira Guerra Mundial no Brasil de uma perspectiva pouco trabalhada na literatura: o cenário musical carioca. Partindo de trabalhos recentes sobre a importância da propaganda empreendida pelas nações em conflito em países neutros, analisamos os impactos de duas ações nesse âmbito: os concertos e as conferências músico-literárias realizadas pela Liga Brasileira pelos Aliados e a estada do músico francês Darius Milhaud como adido cultural no Brasil. Nossa ideia é analisar como os embates culturais, entre uma cultura latina e outra germânica, foram trabalhados por meio desses eventos e contribuíram significativamente para o estreitamento da aliança cultural do Brasil com os países aliados, especialmente a França.

Palavras-chave: música; guerra; propaganda.

\begin{abstract}
This article aims to address the cultural impacts of the First World War in Brazil through a less studied perspective in literature: the musical scene of Rio de Janeiro. Based on recent work on the importance of propaganda by conflicting nations in neutral countries, we analyze the impact of two actions in this area: the concerts and the musico-literary conferences held by the Brazilian League for the Allies and the stay of the French musician, Darius Milhaud, as cultural attache in Brazil. Our idea is to analyze how cultural clashes, between a Latin and a German culture, were debated through these events and contributed significantly to the tightening of Brazil's cultural alliance with the allied countries, especially France.
\end{abstract}

Keywords: music; war; propaganda.

\footnotetext{
* Pesquisadora bolsista de pós-doutorado júnior, Fundação Casa de Rui Barbosa (FCRB). Rio de Janeiro, RJ, Brasil. lpfagundes392@hotmail.com
} 
O governo ... pode ser neutro; nós, brasileiros, somos aliados.

Oscar Guanabarino, 29 jul. 1916

Ao final da crítica à peça Servir, do francês Henri Lavedan, o famoso crítico musical Oscar Guanabarino afirmava categoricamente o posicionamento que, segundo ele, predominava entre brasileiros: eram todos aliados, apesar de o governo brasileiro continuar neutro. ${ }^{1}$ A peça de Lavedan, escrita em 1912, abordava a relação conflituosa entre um pai, extremamente patriótico e devotado ao serviço militar, e seu filho pacifista. Segundo o crítico, um trecho específico da peça empolgava a plateia: a execução do hino francês, a Marselhesa. Suas notas levantavam os espectadores em aplausos frenéticos, que mais pareciam estar em um ato patriótico e não no teatro. Para o crítico, nenhum outro espetáculo havia causado tamanho efeito na plateia, o que era compreensível dado o momento histórico. Guanabarino fazia referência à Primeira Guerra Mundial, que em 1916 alcançava a frota brasileira com o torpedeamento do cargueiro Rio Branco por um submarino alemão (Daróz, 2016, p.59).

A guerra tornava-se cada vez mais "real" para o Brasil, contribuindo para o crescimento de protestos contra a neutralidade brasileira - a favor do posicionamento pró-aliado -, e para o surgimento de movimentos de caráter nacionalista, como a Liga da Defesa Nacional, fundada em setembro de $1916{ }^{2}$ Apesar da pressão e dos sucessivos ataques a vapores brasileiros, o governo brasileiro permaneceu neutro até junho de 1917. Após a revogação da neutralidade, a lei de guerra foi sancionada apenas no final do ano, em 16 de novembro de 1917. A pequena participação brasileira na guerra ${ }^{3}$ atraiu poucos estudiosos, e os impactos culturais da guerra apenas recentemente foram alvo de trabalhos mais aprofundados. ${ }^{4}$

O uso do artigo de Guanabarino para abrir este texto teve como objetivo justamente destacar a importância da cultura francesa na mobilização pró-aliada, representada por um de seus maiores símbolos: a Marselhesa. Mas esteve longe de ser o único. Essa mobilização marcou presença nos eventos culturais realizados pela Liga Brasileira pelos Aliados e nos inúmeros concertos organizados pelo jovem músico francês Darius Milhaud, no Rio de Janeiro. Nesse sentido, escolhemos analisar os impactos culturais da guerra no âmbito do cenário musical carioca, atentando para o lugar que a música ocupou na propaganda cultural aliada, especialmente a francesa, bem como para o referencial estético que ela trouxe, e o quanto ela se conectou, ou não, ao crescente movimento nacionalista perceptível no período. 
A relevância da música na propaganda cultural francesa feita durante a guerra fica patente quando retomamos o pensamento do grande compositor e músico francês Claude Debussy. Para ele, variadas eram as formas de se derrotar o inimigo, e a música, definitivamente, era tão importante quanto tantas outras ferramentas de propaganda cultural (Fulcher, 2005, p.37). Tal pensamento relaciona-se diretamente com o contexto musical francês, que, desde a segunda metade do século XIX, foi marcado pela forte penetração da música do compositor alemão Richard Wagner, identificada com o que havia de mais "moderno" em linguagem musical.

Paralelamente, esse período também foi marcado por um forte sentimento de revanchismo, por conta da derrota francesa na Guerra Franco-Prussiana, aspecto que estaria presente sobretudo na produção de Claude Debussy e Maurice Ravel. Segundo Danieli Benedetti (2013), o revanchismo influenciaria todo o universo político e cultural francês, perceptível em um "sentimento de repugnância a toda e qualquer forma de expressão cultural que viesse de terreno inimigo, em particular da Alemanha" (Benedetti, 2013, p.79). Acompanhava esse movimento um nacionalismo musical expresso na releitura de compositores franceses do século XVIII, tais como François Couperin e Jean-Philippe Rameau. Ou seja, ao mesmo tempo que houve forte influência da cultura germânica, por meio da música de Wagner, houve também um movimento de repulsa a ela, que ganhou força no período da guerra. Essa rejeição à música germânica e, em contrapartida, a ampla defesa da música nacional, levou à exclusão dos compositores alemães, ou austríacos, dos repertórios executados pelo país, especialmente da música de Wagner. A oposição mais radical à execução desse repertório veio na ação de Camille Saint-Saens. O músico pode ser incluído numa miríade de artistas e intelectuais franceses que se mobilizaram durante a guerra e tiveram papel importante e útil na defesa contra a propaganda germânica (Nolan, 2014). Saint-Saens escreveu uma série de artigos denunciando a influência germânica e austríaca na música francesa, publicados no L'Echo de Paris, os quais sugeriam a exclusão da música germânica dos repertórios, sob o argumento de que a arte não era universal - tinha, sim, uma pátria (Fulcher, 2005, p.30).

O pensamento de Debussy e Saint-Saens é deveras interessante para compreendermos um movimento ocorrido nas artes de forma geral. Afinal, a restrição à execução da música do inimigo foi uma ação comum entre as principais potências engajadas no conflito, ocorrendo também na Rússia e na Alemanha (Stites, 1999; Watkins, 2003). Ou seja, como afirmam Aviel Roshwald e Richard Stites (1999), em todas as nações beligerantes a propaganda governamental, as 
artes e o entretenimento foram explorados em níveis diferentes de consciência para glorificar a pátria, demonizar o inimigo e estimular apoio aos objetivos expansionistas de guerra. A intensa politização da arte durante a guerra foi uma das consequências desse quadro, tornando extremamente difícil para artistas, músicos e intelectuais afirmarem neutralidade, ou indiferença, em relação ao conflito.

Essa breve análise do cenário musical francês levanta alguns pontos relevantes acerca da Primeira Guerra Mundial que apenas recentemente começaram a ser explorados pela historiografia, ${ }^{5}$ pois remetem à intensa batalha cultural que se travou nesse momento, materializada no controle de informação e na propaganda. Segundo Stéphane Audoin-Rouzeau e Annette Becker (2000), a guerra é antes de tudo um ato cultural, pois a violência proveniente do conflito não é um ato gratuito, mas sim se alimenta de representações e valores. Audoin-Rouzeau e Becker procuram responder em seu livro a uma questão básica: por que os europeus consentiram, durante 5 anos, em passar por tanto sofrimento e sacrifício sem se revoltar? Essa guerra consentida apoiou-se fundamentalmente na suposta maldade intrínseca do adversário, jamais posta em questão, a qual justificou a luta da civilização contra a barbárie, cristalizada em uma verdadeira "cultura de guerra". ${ }^{6}$ Algo intensamente trabalhado pelas elites intelectuais alemãs, francesas e inglesas, que se empenharam em comprovar tais representações em seus escritos. Os alemães, por exemplo, afirmavam que franceses e ingleses deram primazia ao interesse individual sobre o coletivo, contrariando a tradição alemã e a noção de kultur (Audoin-Rouzeau; Becker, 2000). Já a argumentação antialemã ancorava-se na cultura humanista, na ideia da civilização universal francesa, proveniente de uma longa tradição da Igreja e do universalismo dos direitos do homem e da República, encarnando a "verdade e a luz" contra a kultur alemã, considerada "bárbara" (Audoin-Rouzeau; Becker, 2000), cujo símbolo máximo passou a ser a música de Wagner e o expressionismo, representado pelas composições de Arnold Schoenberg. Nesse sentido, ressalta Glenn Waltkins (2003, p.123), difundiu-se no mundo das artes francês, e também no inglês, a noção de que qualquer trabalho de avant-garde, como o cubismo por exemplo, seria influenciado pela "arte boche", ou seja, "arte alemã". O próprio Debussy expressou tal pensamento ao criticar a obra do compositor russo Igor Stravinsky por se inclinar perigosamente em direção à música de Schoenberg (Waltkins, 2003, p.102).

A argumentação apresentada no campo de batalha cultural era a base da propaganda levada a cabo pelos beligerantes também nos países neutros, e sua 
importância pode ser compreendida no âmbito da "guerra total", ou seja, no engajamento de todos os meios necessários para derrotar o inimigo. ${ }^{7}$ Troy Paddock (2014) define propaganda como um processo de negociação, e não de manipulação, que mobiliza certos valores e ideias, cuidadosamente pensados e selecionados para uma determinada audiência, tomando como base as tendências da opinião pública. Nesse sentido, os aliados contavam com certas vantagens, pois além de monopolizarem as comunicações, ${ }^{8}$ era considerável a influência da cultura francesa em vários países latino-americanos, como no Brasil e na Argentina. A historiadora argentina María Inés Tato (2014) explora tal questão com o estudo da propaganda difundida pelas nações aliadas e pelo Império Alemão na Argentina, na forma de livros, brochuras e outras publicações, mas que não resumiam, é claro, toda propaganda veiculada, podendo essa ser encontrada em outras formas de expressão cultural, como filmes, pôsteres, cartões-postais patrióticos ou conferências. Para tanto, aliados e germânicos utilizavam-se de agências de inteligência, em um esforço para desenvolver a propaganda adequada às diversas nações.

Por conseguinte, o estudo dos impactos culturais da guerra em países neutros, como o Brasil, apresenta relações estreitas com a propaganda levada a cabo nesse período pelas nações beligerantes, agindo diretamente nos embates acerca da manutenção ou não da neutralidade, tornando obrigatório repensar identidades, valores, tradições e representações. Enfim, a guerra demandou uma definição por parte de cada sociedade, uma definição que não ocorreria sem inúmeros conflitos e ambiguidades. Porém, antes de abordarmos tais ações, é importante pensarmos o grau de penetração da música e cultura francesas no cenário musical carioca, especialmente no Instituto Nacional de Música (INM), local privilegiado para se pensar a construção de uma identidade musical nacional após a proclamação da República, em 1889.

A instalação do INM no lugar do Conservatório Imperial, graças à atuação de personagens como Leopoldo Miguez (primeiro diretor), Alberto Nepomuceno e Francisco Braga, tornou clara a estreita relação entre República e música. A pronta adesão de vários membros da sociedade dos músicos ao novo regime era sintomática, aponta Avelino Pereira (2007, p.67), do conteúdo republicano de suas ideias e atos, permitindo situar nesse momento a fundação, também, de uma República Musical no Rio de Janeiro. As bases dessa República Musical se assentavam justamente em oposição às do Conservatório Imperial. Assim, deixou-se de lado a escola italiana, que tanto influenciou os compositores brasileiros, como Carlos Gomes, e voltou-se para a tradição musical germânica, especialmente a produção de Richard Wagner. Foi por 
meio de uma série de concertos sinfônicos, realizados na primeira década republicana, ${ }^{9}$ que o repertório wagneriano foi trazido para o Brasil. Fato que teve significado muito importante, pois tal repertório foi utilizado para romper com os símbolos culturais da monarquia, possibilitando uma nova música, uma "música do futuro", como ressaltou Maria Alice Volpe (2001). Porém, observa essa autora, a difusão do wagnerismo entre os compositores brasileiros ocorreu por intermédio da França, expandindo-se em ambiente predominantemente francófilo.

Após essas considerações sobre as influências estéticas no cenário musical brasileiro, cabe perguntar: qual seria o impacto do boicote a Wagner proposto por Saint-Saens? Segundo Rodrigues Barbosa (apud Pereira, 2007, p.283), Alberto Nepomuceno teria protestado contra o boicote, porém, na prática, o músico reduziu consideravelmente os números wagnerianos em seus programas, e mesmo Beethoven foi excluído, afirma Avelino Pereira (2007, p.283). Em rápida pesquisa nos repertórios da Sociedade de Concertos Sinfónicos, ${ }^{10}$ entre 1914 e 1918, percebemos que no concerto do dia 9 de outubro de 1914 Wagner foi incluído, figurando entre Carlos Gomes, Leopoldo Miguez e Massenet. Outro concerto, em 31 de julho de 1915, sob a regência de Francisco Braga, e no qual figurava o jovem violoncelista Heitor Villa-Lobos, incluiu a Cavalgada das Valquírias, do compositor alemão. Cabe, porém, observar as datas dos concertos, ambos realizados no começo da guerra. Porém, uma nota do crítico Oscar Guanabarino, publicada após a guerra, reforça a ideia de que ocorreram tentativas de boicote, especialmente das óperas de Wagner. Segundo o crítico, a denúncia teria vindo da Associação Wagneriana de Buenos Aires, e relatava o fato de que alguns editores franceses e italianos procuraram sistematicamente dificultar a execução da música wagneriana nos teatros dos países latinos (Jornal do Commercio, 30 set. 1919). Outro exemplo dessa preocupação com o que era apresentado na América Latina deu-se com o músico francês André Messager, que foi recriminado por executar Wagner em seus concertos em Buenos Aires, em 1915; uma ação considerada "antipática", por ser ele chefe de uma orquestra francesa que se apresentava em país neutro (Buch, 2004, p.10).

No caso dos músicos brasileiros do INM, percebemos o engajamento de um pequeno grupo em prol da causa aliada, sendo Alberto Nepomuceno o mais ativo entre eles. Em novembro de 1917, o compositor enviou um requerimento ao Conselho Docente do INM, para que o instituto manifestasse publicamente seu apoio e solidariedade à decisão brasileira de declarar guerra à Alemanha. Nepomuceno também produziu composições inspirada no 
conflito, como Oração à pátria, de 1914; Tambores e cornetas, de 1918, com texto de Osório Duque-Estrada, e a Saudação à bandeira, de 1919, com texto de Aquino Correia (Pereira, 2007, p.281-282). Enfim, em companhia do pianista Joaquim Barroso Netto e do barítono Carlos Alves de Carvalho, respectivamente professores de piano e canto do INM, Nepomuceno participou ativamente dos eventos promovidos pela Liga Brasileira pelos Aliados (LBA).

A LBA foi fundada em 17 de março de 1915 no Rio de Janeiro, por José Veríssimo, Graça Aranha, Eliseu Fonseca Montarroyos, Augusto de Araújo Gonçalves e Antônio dos Reis Carvalho. Tinha como presidente honorário Ruy Barbosa e como vice-presidente José Veríssimo, e sua sede ficava no prestigioso Clube de Engenharia, localizado na Avenida Rio Branco, concedido por Paulo de Frontin, presidente do Clube e membro da Comissão Executiva da LBA. Como bem ressaltou Livia Pires, considerando sua composição e atuação, a Liga pode ser pensada como uma organização composta pela elite cultural ${ }^{11}$ brasileira por conta da considerável influência e poder de ressonância de seus discursos, a ponto de "se autodenominar representante maior da opinião pública brasileira no tocante à guerra europeia” (Pires, 2013, p.153). Para pensarmos seu grau de influência, é deveras relevante atentarmos à formação de seus principais membros, realizada nas mais distintas instituições de ensino do país. Tais membros pertenciam também a outras instituições de destaque na sociedade brasileira, e alguns exemplos são: Rodolpho Bernardelli, diretor da Escola Nacional de Belas Artes; Miguel Couto, presidente da Academia Nacional Medicina; Graça Aranha, Coelho Neto e Rui Barbosa, da Academia Brasileira de Letras. Além disso, a LBA contava com membros atuantes na imprensa, como os críticos de música Luiz de Castro e Rodrigues Barbosa, e na política, como os senadores Antônio Azeredo, Lauro Sodré e Rui Barbosa. ${ }^{12}$

Enfim, composta por intelectuais e políticos ilustres do cenário nacional, a Liga tinha como objetivo promover a causa dos Aliados entre a população brasileira, bem como prestar assistência moral e beneficência a essas nações (Pires, 2013). Seu canal de propaganda aliadófila eram preferencialmente os jornais da capital federal, nos quais publicava frequentemente manifestos, artigos e correspondências trocadas com diversas personalidades importantes da Tríplice Entente. Além dos jornais, a Liga também publicou diversos panfletos, reproduzindo palestras proferidas por seus ilustres membros, ou traduções de obras estrangeiras, como por exemplo o panfleto Os crimes alemães, publicado em parceria com o Comitê de Propaganda Franco-Belga. Segundo Pires (2013, p.75), tais panfletos não eram comercializados, mas distribuídos de forma 
gratuita na sede da Liga e nas redações dos principais jornais e revistas da capital.

Porém, os impressos não eram o único veículo de propaganda utilizado. A promoção de eventos festivos e artísticos por parte da Liga, especialmente em seu primeiro ano de atividades, foi tão intensa que lhe valeu a alcunha de "sociedade musical e dançante" ou "clube dramático, recreativo e literário" (Pires, 2013, p.92), dados por Lima Barreto. Deve-se destacar, todavia, que a Liga passou por modificações após a morte de José Veríssimo, no início de 1916, fato que provocou até mesmo a saída de alguns de seus membros e a diminuição dos eventos beneficentes, que deram lugar à atuação mais retórica (Pires, 2013). Seguiram-se como substitutos de Veríssimo, na vice-presidência da LBA, Afrânio Peixoto e Antônio Dias, cada um dos quais ficou pouco tempo no cargo. Por fim, assumiu o professor e jurista Manoel de Souza Sá Vianna, que permaneceu até sua extinção, em 1919.

Independentemente das alterações que sofreu durante a guerra, o fato é que a LBA promoveu intensa campanha de opinião com o propósito de ganhar a sociedade brasileira para a causa aliada, influenciando até mesmo a abertura de outras ligas com mesmo propósito por todo o Brasil, o que resultou na construção de uma "verdadeira rede nacional da aliadofilia" que sobreviveu até o final do conflito, como apontou Olivier Compagnon (2014, p.68). Além do apoio de intelectuais, artistas e políticos nacionais, a Liga também era próxima do Comité France-Amérique e da Legação Belga, atuando fortemente na divulgação de publicações dedicadas à denúncia das atrocidades alemãs, produzidas pelo Comitê de Propaganda Franco-Belga. Nesse sentido, vale destacar a atuação de Graça Aranha em Paris, presença marcante em eventos intelectuais e especialmente no Comitê Franco-Brasileiro, auxiliando a divulgação na França das manifestações da Liga. Enfim, a Liga foi um importante ponto de apoio para os interesses propagandísticos, não apenas da França e da Bélgica, mas também da Inglaterra, sendo requisitada para divulgar à sociedade brasileira os "justos" motivos da luta dos aliados, que se levantava contra a barbárie e pela justiça e liberdade do mundo.

No período em que José Veríssimo esteve à frente da Liga, de março de 1915 a fevereiro de 1916, ocorreram seis grandes eventos e duas séries de conferências; a primeira delas teve acompanhamento musical, já a segunda série, aparentemente, não chegou a ser executada até o fim.

O primeiro grande evento organizado pela Liga homenageou a Bélgica, por conta do aniversário do rei Alberto I, e realizou-se em março de 1915 no Teatro Lírico. Além da Liga, estava envolvido também na organização do 
evento o Comitê Belga (fundado pela Legação Belga), que tinha como objetivo arrecadar a renda produzida pelo evento e enviá-la às famílias belgas e à Cruz Vermelha Belga. O evento contou com discurso de Coelho Neto, com uma composição inédita do pianista Joaquim Barroso Netto em homenagem ao dramaturgo, poeta e ensaísta belga Maurice Maeterlinck, e com o poema "Ode aos belgas” do literato Goulart de Andrade (A Noite, 1 abr. 1915). Também fazia parte do programa o poema "L’aigle du casque", de Victor Hugo, trecho da coletânea La legende des siècles, onde o famoso poeta e literato francês retratava a luta do bem contra o mal; apesar de escrito no final do século XIX, servia como base para a retórica aliada, e seria repetido em outros eventos organizados pela Liga. Contudo, o evento foi alvo de críticas, publicadas em artigo não assinado no jornal O Paiz. Sob o título de "Filantropia para uso externo" (O Paiz, 9 abr. 1915), o artigo argumentava que apesar de homenagear o rei belga e de destinar a renda à Cruz Vermelha Belga, a iniciativa merecia "certas ponderações”. A principal delas era a existência de graves problemas de cunho nacional, carentes de iniciativas de caráter altruísta, e que eram mais importantes do que a "guerra europeia".

Em meados de abril, com a visita da missão francesa chefiada pelo senador Pierre Baudin, a Liga não perdeu a oportunidade de organizar um evento em sua homenagem. A missão chegou ao Brasil em 8 de abril de 1915 e foi recebida pela Liga, representada por Graça Aranha. Era uma missão de cunho econômico, voltada para a América Latina, cujo objetivo, segundo o próprio Baudin, era a "defesa econômica e moral de seu país" (O Paiz, 22 abr. 1915). Já no início da guerra, percebe-se a preocupação com o posicionamento da América Latina perante a conflagração. Reforça-se aqui a ideia de que, desde o início do conflito, as nações europeias procuraram angariar aliados na América Latina, levando o conflito para fora da esfera europeia.

A festa organizada para homenagear Baudin ocorreu no Teatro Lírico, e também tinha como objetivo recolher donativos para a Cruz Vermelha Francesa. O programa incluiu várias interpretações do hino francês, a Marselhesa, mas não dispensou os hinos dos outros países aliados, como Inglaterra, Rússia e Bélgica. Outros itens do programa eram: a composição Le Colibri do músico francês Ernest Chausson; um trecho da ópera Le Caïd, de Ambroise Thomas; ária da cena lírica, em um ato, de $O$ filho prodigo, de Claude Debussy, e "Amour sacré de la patrie", da ópera A muda de Portici, de Daniel Auber. A apresentação teve como regente Gabriel Dupriche e contou a participação do barítono Carlos de Carvalho e do pianista Ernani Braga (O Paiz, 20 abr. 1915). 
O próximo evento organizado pela Liga tratou novamente de homenagear a França, em razão do 14 de julho, e foi realizado no Teatro Lírico, constituindo-se em um festival músico-literário com a participação da Alberto Nepomuceno, que regeu uma orquestra de quarenta professores. No programa literário destacam-se o poema de caráter patriótico "Hymne”, de Victor Hugo; o poema "L'enfant de sept ans", do romancista, poeta e jornalista francês Miguel Zamacois, que denunciava a violência de tropas alemães contra um garoto de 7 anos; e "En avant", do poeta e político Paul Dérouléde, um dos líderes do revanchismo francês. Outros números foram o "Soneto a França", composto especialmente para a festa por Goulart de Andrade e recitado pelo autor, e o discurso "Saudação a França", por Arthur da Rocha Pinto. Na programação musical, grandes nomes da música francesa, como Georges Bizet e Camille Saint-Saens, sendo a produção nacional representada pelo Hino à Alsácia Lorena, composto por Alberto Nepomuceno especialmente para a ocasião, com versos de Osório Duque Estrada, os quais foram interpretados pelo professor de canto do INM, Carlos de Carvalho; pelo poema lírico para canto Ophelia, de Henrique Oswald, e por um trecho da ópera O Guarani, do consagrado compositor Carlos Gomes (A Noite, 9 jul. 1915). Percebe-se a grande participação de nomes importantes da intelectualidade e do cenário musical nacional. Afinal, Alberto Nepomuceno ocupava o importante cargo de diretor do Instituto Nacional de Música, conferindo ao evento grande prestígio e também legitimando uma afinidade cultural entre as nações. Ainda em 1915, o músico participaria de outro grande programa organizado pela Liga no Teatro Municipal, em benefício às vítimas de guerra belgas (O Paiz, 4 nov. 1915).

O mês de julho foi palco de outro evento organizado pela Liga: uma grande festa de caridade, em comemoração ao aniversário da rainha belga, Elisabeth, cujo objetivo era coletar doações para as crianças belgas expatriadas e também para as crianças prejudicadas pela seca no norte do Brasil. Ou seja, as críticas ao primeiro evento organizado pela Liga foram, em parte, acolhidas. A grande festa foi organizada com auxílio do jornal A Noite, na Quinta da Boa Vista, e contou com a participação de vinte bandas de música (cedidas pelo governo) e uma variedade de atrações (A Noite, 24 jul. 1915). Outro evento nesse mesmo estilo foi organizado no início de 1916, no Campo de Santana, em benefício das caixas escolares municipais e da Cruz Vermelha dos Aliados. O festival contou com cinematógrafo (exibindo filmes inéditos da Grande Guerra, fornecidos pelo governo francês), dança e concurso dos grandes clubes carnavalescos (O Paiz, 14 jan. 1916). Ambos os eventos foram, sem dúvida, os de cunho mais popular organizados pela instituição, e tinham como objetivo 
atrair um público mais variado; nesse sentido, vale destacar que a festa da Quinta da Boa Vista obteve sucesso considerável, com a presença de cerca de 30 mil pessoas (Pires, 2013, p.86).

O último grande evento promovido pela Liga ocorreu em agosto de 1917, e consistiu em um festival músico-literário em homenagem à Grã-Bretanha e em benefício dos belgas, realizado no Teatro Lírico. A primeira parte do programa foi dedicada à execução dos hinos nacionais das nações aliadas, inclusive o de Portugal, e de uma saudação à Inglaterra, feita pelo senador Rui Barbosa. Na segunda parte do evento, os poemas de Victor Hugo reaparecem no repertório ("Hymne" e "L’aigle du Casque"), junto às composições de Carlos Gomes, agora representado por trecho de sua ópera Lo Schiavo, e de outros compositores brasileiros que gozavam de prestígio à época - Elpídio Pereira e João Octaviano Gonçalves (O Paiz, 5 ago. 1917).

A partir dessa exposição, percebe-se a participação de músicos importantes na causa aliada, bem como o engajamento de notáveis do cenário literário, artístico e político nos eventos da LBA, que foi, definitivamente, a primeira organização brasileira a estimular o debate acerca do posicionamento brasileiro no cenário de conflito, justificando seu apoio aos aliados numa aliança cultural, manifesta no repertório literário e musical. Algo perceptível nas séries de conferências por ela apresentadas, nas quais a música também ocupou papel relevante, como veremos a seguir.

A primeira palestra da primeira série, realizada em 10 de junho de 1915, tinha como tema "A música russa", e foi proferida pelo musicólogo Luís de Castro. Segundo o jornal O Paiz (10 jul. 1915), a temática e o propósito da conferência (a favor dos polacos russos - poloneses que viviam nos territórios dominados pela Rússia, dominação que terminou em agosto, com o avanço do exército austríaco) foram sugeridos pelo escritor Henryk Sienkiewicz e pelo pianista e diplomata Ignacy Jan Paderewski, ambos poloneses. Segundo o Jornal do Commercio, a palestra de Luís de Castro teve como objetivo realizar um estudo histórico e crítico da música russa, acentuando a importância do surgimento do "grupo dos cinco" - Modest Mussórgski, César Cui, Nikolai Rímski-Korsakov, Mily Balakirev e Aleksandr Borodine - "que, como uma unidade de vista admirável, e obedecendo a mesma corrente de ideias, criaram a Escola de música russa que se expandiu vitoriosa na eclosão do sentimento musical patriótico". Ao final da conferência de Luís de Castro, falou o representante da Rússia no Brasil, que elogiou "a homenagem que acabava de prestar com tanto talento, à arte musical russa” (Jornal do Commercio, 11 jun. 1915). 
Apesar de a palestra ter focado o "grupo dos cinco", compositores russos renomados como Mikhail Glinka, e outros mais modernos, como Vladimir Rebikoff, não faltaram no programa executado. Tais nomes da moderna escola russa eram conhecidos do público carioca, pois vários deles constavam da programação organizada por Alberto Nepomuceno e Francisco Braga para a Exposição Comemorativa da Abertura dos Portos às Nações Amigas, ocorrida em 1908, no Rio de Janeiro (Lago, 2010, p.42-43).

Porém, um comentário na coluna "Microcosmo", de Carlos de Laet, em O Paiz (16 jun. 1915), chamou nossa atenção. Segundo Laet, Luís de Castro era um "intransigente admirador de Wagner", mas que, no momento, não falava mais no músico alemão, contentando-se em elogiar a música russa. A mudança de atitude do musicólogo estava relacionada justamente à batalha cultural provocada pela guerra, que, naquele ano de 1915, era animada pela fundação da LBA, e pouco tempo depois o seria pela Liga Brasileira Pró-Germânia. ${ }^{13} \mathrm{Ou}$ seja, mesmo ocorrendo uma intensa mobilização pró-aliada, é possível destacar algumas ações em sentido oposto; outro exemplo são os artigos do médico Henrique da Rocha Lima, que atuava no Instituto de Doenças Marítimas e Tropicais de Hamburgo desde 1909, o qual tomou a iniciativa de publicar textos pró-Alemanha na imprensa brasileira, especificamente no Jornal do Commercio (Silva, 2015). Enfim, nesse contexto polarizado era possível que o boicote à cultura alemã, representada pela música de Wagner, aparecesse em ações pontuais, como a do maestro Nepomuceno e a do musicólogo Luís de Castro.

As conferências seguintes prosseguiram na temática cultural, focando a cultura belga: a $2^{\text {a }}$ conferência, ocorrida em 17 de junho de 1915 no salão do Jornal do Commercio, foi proferida pelo cônego belga Thomaz de Aquino, e versou sobre o "heroísmo" de seus conterrâneos (O Paiz, 15 jun. 1915); a outra, realizada em $1^{\circ}$ de julho de 1915 pelo advogado, escritor e jornalista paraense Flexa Ribeiro, teve como tema os "Artistas belgas" e contou com a participação de Alberto Nepomuceno, que executou números de Cesar Frank (O Paiz, 30 jun. 1915). Sobre algumas conferências temos apenas o título, o que impossibilita mais reflexões; outras, porém, contaram com a publicação de seu sumário pelos jornais. É o caso da conferência realizada pelo intelectual pernambucano Carneiro Leão, em 17 de agosto de 1915, sob o título de “A alma latina”, cujo propósito era provar a superioridade da "alma latina" sobre uma suposta "alma germânica" (O Paiz, 17 ago. 1915).

Assim, podemos supor que a $3^{\text {a }}$ conferência, realizada por Alcides Maya, cujo título era "Ideais americanos e prussianos", tinha objetivos semelhantes, 
ou seja, comparar as duas culturas, comprovando a superioridade de uma sobre a outra. Além das séries, a Liga também promoveu grandes conferências, uma delas sobre a Batalha do Marne, proferida por Miguel Calmon a pedido da Liga, no Teatro Municipal, em 28 de setembro de 1915, cuja renda foi enviada às vítimas belgas. A Bélgica foi o tema das conferências seguintes: a do padre belga Van Emlen, em dezembro de 1915, intitulava-se "A Bélgica antes e depois da invasão"; já a conferência da jornalista belga Eva van Emdem, em benefício da Cruz Vermelha Belga e das vítimas do incêndio do morro de Santo Antônio, realizada em 9 de junho de 1916, sob o título de "O martírio da Bélgica", versava sobre o heroísmo belga e a barbárie alemã (O Paiz, 9 jun. 1916).

Enfim, percebe-se aqui uma importante estratégia de propaganda por parte da Liga, como bem apontou Livia Pires (2013), que remete à escolha de testemunhas oculares da guerra, ou de figuras respeitáveis do cenário nacional, como Miguel Calmon, para proferir tais palestras, algo que muito auxiliava na "fertilização" da opinião pública brasileira numa direção pró-aliados. Nesse sentido, podemos dizer que a inserção da música (e de célebres músicos nacionais), além de atrair público, reforçava um sentimento comum de latinidade, robustecendo esteticamente os laços entre a música brasileira e a francesa, principalmente.

Assim, o jovem músico francês Darius Milhaud encontraria terreno fértil para atuar na organização de uma série de eventos beneficentes e das relações que construiu com importantes músicos brasileiros; podemos dizer que Milhaud preencheu uma lacuna deixada pela LBA, que, a partir de 1917, diminuiu consideravelmente sua atuação mediante eventos culturais.

Em janeiro de 1917, o renomado maestro francês André Messager escreveu ao músico brasileiro Alberto Nepomuceno, ex-diretor do Instituto Nacional de Música, uma carta recomendando um jovem músico francês aos seus cuidados. Esse músico era Darius Milhaud, "encarregado de uma missão de propaganda artística no Brasil pelo governo francês”, informava o remetente. Missão para a qual necessitaria do auxílio do maestro brasileiro, mediante fornecimento de informações sobre "o movimento musical" brasileiro e dos meios para "tornar conhecida, através de concertos e audições, a produção de nossa jovem escola francesa”. Na carta, Messager também sugeria que Nepomuceno apresentasse Milhaud a dois importantes críticos musicais brasileiros, Luís de Castro e a Rodrigues Barbosa, "os quais sustentam tão generosamente em seus artigos nossa música e me dispensaram uma acolhida tão amigável". ${ }^{14}$ Praticamente desconhecido no Brasil, Milhaud já contava com uma bela carta de apresentação, que não seria a única. 
Outra carta foi enviada, em nome do Conservatório e do Ministério da Instrução Pública e de Belas Artes francês, por Xavier Leroux, que fora professor de Milhaud no Conservatório Nacional de Música, a José de Freitas-Valle, figura influente na sociedade paulista, que transformou sua casa, a famosa Villa Kyrial, em ponto de encontro de artistas, literatos e políticos, promovendo saraus literários, audições musicais, banquetes e ciclos de conferências (Camargos, 2000). A carta apresentava Milhaud "como um dos músicos mais brilhantes da jovem escola francesa” (Camargos, 2000, p.47), e solicitava o acolhimento do músico no rico ambiente cultural da Villa Kyrial.

As cartas enviadas permitem considerar que a missão de Milhaud no Brasil envolvia uma importante atuação cultural na área da música. Ou seja, tinha como objetivo estreitar ainda mais os laços que uniam as músicas francesa e brasileira, contribuindo assim para a causa francesa no âmbito da intensa batalha cultural que se travava no momento. Tal função propagandística é especificada pelo próprio Milhaud em carta a Rui Barbosa, em 6 de março de 1917, na qual o músico se apresenta como secretário particular de Claudel, enviado pelo seu governo ao Brasil em missão de propaganda, e requisita um encontro para conhecer o ilustre brasileiro (Perrin, 2009, p.9).

Milhaud chegou ao Brasil em fevereiro de 1917, em pleno carnaval. A festa popular impactou profundamente o músico, que registrou em sua autobiografia o imediato fascínio com os ritmos da música popular, levando-o a comprar partituras de muitos maxixes e tangos, no intuito de tentar tocá-los, “com seu ritmo sincopado" (Milhaud, 1953, p.75). Já o contato com os músicos do INM ocorreu na casa de Henrique Oswald, onde conheceu os músicos que seriam seus principais parceiros em sua estada no Brasil: Godofredo Leão Veloso, sua filha Nininha Veloso Guerra, e seu genro, Oswald Guerra. Foi lá, também, que conheceu Francisco Braga, porém, a atuação com os Veloso-Guerra seria, de longe, a mais profícua. A afinidade veio no gosto pela música contemporânea francesa, cultivado, principalmente, por Leão Veloso, professor de piano do INM.

Em sua autobiografia o músico revela a forte influência de Debussy em suas composições, e também das peças e versos do literato belga Maurice Maeterlinck. Já a música de Wagner não lhe causava apreço, e em sua opinião era "deplorável a influência dessa música na francesa" (Milhaud, 1953, p.26). Porém, tais impressões não significavam que Milhaud fosse adepto do antigermanismo, argumenta Lina Maria Ribeiro de Noronha (2012, p.91), mas sim antiwagneriano. Consequentemente, execrava os compositores que se espelhavam em Wagner, como Vincent D'Indy ou Cesar Franck, pois considerava 
que essa influência não trouxera ganhos à música francesa. A crítica de Milhaud estava na diferença que concebia entre os pensamentos latino e germânico, algo que influenciava diretamente as formas de compor, conectada claramente à nacionalidade do compositor. Milhaud assumia-se, então, como um compositor de cultura latina. Segundo Noronha (2012, p.92), tal conceito de latinidade tinha como base os ideais provenientes da Antiguidade Clássica, e eram capazes de conectar diferentes culturas presentes na própria identidade do músico: as culturas francesa, provençal e a judaica. A relação de alteridade com o universo cultural germânico também contribuía, é claro, para a construção dessa identidade latina.

O primeiro grande concerto que contou com a participação e a organização de Milhaud ocorreu em 30 de junho, no salão do Jornal do Commercio, sob os auspícios de d. Maria Augusta, esposa de Rui Barbosa, em benefício do Hospital Brasileiro de Paris, inaugurado em 29 de maio. O concerto organizado procurou harmonizar grandes nomes das músicas francesa e brasileira contemporâneas, como Charles Koechlin, Maurice Ravel, Francisco Braga e Henrique Oswald. O primeiro número foi reservado à música barroca francesa, representada por François Couperin, algo que seria repetido nos concertos seguintes. Milhaud apresentou sua Sonate para piano e dois violinos, inédita no Brasil, e Alberto Nepomuceno também fez a primeira audição pública de sua peça para piano e canto Le miracle de la semence (O Paiz, 25 jun. 1917). Baseada em poema homônimo de Freitas-Vale, a composição foi marcada pela singularidade, pois fazia mais de 20 anos que Nepomuceno não compunha em francês, sendo portanto elogiado pela crítica por seus vínculos com a moderna música francesa (Pereira, 2007, p.288).

O concerto seguinte, realizado em julho, ocorreu no Lycée Français, como parte da série Hora Artística, promovida anualmente pela instituição. Milhaud organizou um concerto dividido em duas partes: a primeira era ocupada novamente pelo barroco francês, representado pela música de Jean-Philippe Rameau, que dividia o espaço com uma composição de Mozart (único compositor alemão incluído nos concertos organizados exclusivamente por Milhaud), seguida por uma sessão de compositores românticos do século XIX, como Chopin e Edvard Grieg, acompanhados do brasileiro Henrique Oswald. A segunda parte era praticamente toda dedicada à música francesa contemporânea, e contava com a primeira audição de uma peça de Milhaud, a $2^{e}$ sonate pour piano e violon" (a primeira composta no Brasil) e composições de Claude Debussy, Erik Satie e, novamente, do brasileiro Oswald. É pertinente destacar aqui a peça de Debussy escolhida para figurar no programa: Noel pour les 
enfants qui n'ont pas de maison, composta no final de 1915, refletia a revolta do renomado músico francês com a destruição provocada pela guerra (Benedetti, 2013, p.98). A peça foi amplamente utilizada pela propaganda francesa, com o intuito de divulgar as crueldades alemãs para com as crianças francesas e belgas, e seria incluída em outros programas organizados por Milhaud.

As críticas referentes aos concertos do músico francês variaram muito: além de Oscar Guanabarino, que escrevia na coluna Artes e Artistas do jornal O Paiz, temos também Rodrigues Barbosa, no Jornal do Commercio. Barbosa era defensor das novas tendências, e destacava em sua crítica o fato de a $2^{a}$ Sonata ter sido escrita no Rio, ou seja, era "uma sonata carioca por nascimento, francesa e modernista pela escola, ou antes pelo seu modo de ser". E resumia sua admiração pela composição de Milhaud, dizendo que o que ouvira "era belo ... era novo ... era sentido, porque continha uma parcela de humanidade" (Jornal do Commercio, 8 jul. 1917).

A diferença no tom das críticas de Rodrigues Barbosa para as de Oscar Guanabarino é significativa. Poucos dias depois da apresentação no Liceu, Milhaud participaria de outro concerto, organizado e promovido pelo Instituto Nacional de Música, no qual apresentou novamente sua $2^{a}$ Sonata. Escreveu o crítico musical que Darius Milhaud era o "ardiloso compositor moderno, de técnica bizarra e fantasioso nas suas concepções, fruto do ambiente artificioso criado por [Gustave] Charpentier, exagerado por Debussy”. Guanabarino deixava clara sua incompatibilidade com Debussy e seus descendentes que, segundo ele, seguiam "servindo aos caprichos de ritmos desordenados, com sacrifício da poesia musical, da sua alma, da sua verdadeira estética” (O Paiz, 11 jul. 1917). Para Guanabarino, a obra de Milhaud respondia perfeitamente às características da produção artística no século XX por ser esse o

século de arte anarquizada, mas de harmonia com a anarquia do século de que a guerra alemã é consequência lógica. Aceitando a escola que já se impõe, forçada é a crítica a reconhecer nessa composição grandes qualidades pelo artista amador que entre nós se recomenda, não só por esse fato, mas também por pertencer à legação da França. (O Paiz, 11 jul. 1917)

O texto do crítico revela suas contradições. De gosto conservador, Guanabarino via como "sem volta" o caminho que tomava a estética musical, influenciada pelo modernismo francês, que apesar de desagradá-lo, configurava como representante da causa aliada contra a barbárie alemã. Outro ponto 
interessante é a consideração acerca de Milhaud, referido como "artista amador”, porém de qualidade, especialmente "por pertencer à legação da França”. $\mathrm{O}$ argumento chama atenção para o fato de que a influência de Milhaud, e sua larga atuação, não podem ser desvinculadas da missão Claudel e das "credenciais" que isso lhe fornecia. Reforça também a importância do lobby cultural pretendido pela missão.

No segundo ano de sua estada no Brasil, Milhaud organizou o Festival Debussy, em homenagem ao prestigiado compositor francês, que havia falecido em março de 1918. Realizado no dia 2 de maio no salão nobre do Jornal do Commercio, o evento contou com a participação de Regis de Oliveira, Nininha Velloso Guerra, Godofredo Leão Velloso e Nicanor Nascimento; recebeu o patrocínio das legações francesa e inglesa, sendo a renda do evento revertida em benefício dos exércitos da França e da Inglaterra. No repertório, as últimas obras do compositor recém-falecido, dentre elas En blanc et noir - composta no verão de 1915 e dedicada aos amigos mortos na guerra, a composição para dois pianos é considerada uma obra-prima de Debussy, uma de suas contribuições mais importantes para o cenário musical francês no período da guerra (Benedetti, 2013, p.86). Assim, mesmo considerando-se que as obras mais relevantes de Debussy já haviam sido incorporadas ao repertório sinfônico e pianístico carioca antes da Primeira Guerra Mundial, por intermédio de regentes como Nepomuceno e pianistas como Nininha Veloso Guerra, é possível dizer que, no curto período entre a chegada de Milhaud e a realização da Semana de Arte Moderna em São Paulo, a vida musical carioca sofreu um verdadeiro "bombardeio" de música moderna francesa, com foco na obra de Debussy $^{15}$ (Lago, 2010, p.51).

Com base nos concertos por ele organizados, ou que contaram com sua participação, percebe-se que a atuação de Milhaud contribuiu, por um lado, para o aprofundamento da segmentação entre o mundo germânico e o latino, e por outro, para o estreitamento dos laços que ligavam a música erudita brasileira à francesa. Portanto, é possível pensar que atuou - como aponta Manoel Corrêa do Lago - como um verdadeiro ativista cultural; porém, devemos acrescentar, com conexões estreitas com a propaganda e a mobilização cultural francesas durante a guerra. Uma relação que é clara, se tomarmos, por exemplo, o artigo precioso de Oscar Guanabarino no qual o crítico analisa a música apresentada por Milhaud, compreendo-a no âmbito de um mundo em guerra. Além disso, é preciso lembrar que os vários concertos organizados eram sempre voltados para angariar fundos para a Cruz Vermelha dos países aliados, para os soldados feridos ou algum outro grupo desamparado pela guerra. 
A princípio, podemos pensar que a atuação da Liga e de Milhaud não teve muita influência em razão da francofilia da sociedade brasileira pré-guerra, fato comprovado pela própria mobilização inicial pró-aliados. Além disso, o próprio compositor afirmaria posteriormente que a música austro-alemã, com o movimento de Arnold Schoenberg, era pouco conhecida no Brasil. ${ }^{16}$ Porém, uma conjectura de Bruno Kiefer sobre a vida musical no Rio de Janeiro entre os anos 1900 e 1922 nos chamou atenção. Segundo Kiefer (1986, p.17), "Não fosse a Primeira Guerra Mundial, talvez tivessem entrado, naqueles anos, obras de Stravinsky, Schoenberg, Béla Bartók e outros compositores que inauguraram o século XX em música”. Para Kiefer, a guerra interrompe todo um processo de "atualização" do cenário musical, que vinha se desenrolando desde o início do século, e impacta especialmente na percepção da cultura germânica, representada aqui na música de Wagner e no desconhecimento da música de Schoenberg. Nesse sentido, concordamos com Avelino Pereira (2007) quando este afirma que o sucesso da missão de Milhaud pode se comprovar pelo reforço da influência francesa sobre a música de Nepomuceno e no seu desconhecimento da música austro-alemã contemporânea. Enfim, a ação da Liga e de Darius Milhaud deixa evidente a importância de se estudar os impactos culturais da Primeira Guerra Mundial no Brasil, período de intensa propagada aliada e de afirmação da cultura latina, e que deu o tom ao movimento nacionalista nascido nesse momento.

\section{FONTES PRIMÁRIAS}

Fundação Biblioteca Nacional/RJ. Hemeroteca Digital. Disponível em http://bndigital. bn.gov.br/hemeroteca-digital/

Jornal do Commercio (Rio de Janeiro).

A Noite (Rio de Janeiro).

O Paiz (Rio de Janeiro).

\section{REFERÊNCIAS}

ANDRADE, Clarissa B. L. A Gazeta Musical: positivismo e missão civilizadora nos primeiros anos da República no Brasil. São Paulo: Ed. Unesp, 2013.

AUDOIN-ROUZEAU, Stéphane; BECKER, Annette. 14-18, retrouver la Guerre. Paris: Gallimard, 2000. 
BENEDETTI, Danieli V. L. Obras de guerra: a produção musical francesa durante os anos da Primeira Guerra Mundial. São Paulo: Annablume; Fapesp, 2013.

BUCH, Esteban. "Les Allemands et les Boches": la musique allemande à Paris pendant la Première Guerre mondiale. Le Mouvement Social, v.3, n.208, p.45-69, 2004.

CAMARGOS, Marcia. Villa Kyrial: crônica da Belle Époque paulistana. São Paulo: Ed. Senac, 2001.

COMPAGNON, Olivier. O adeus à Europa: a América Latina e a Grande Guerra. Rio de Janeiro: Rocco Digital, 2014.

CORREIA, Silvia Adriana B. Cem anos de historiografia da Primeira Guerra Mundial: entre história transnacional e política nacional. Topoi, Rio de Janeiro, v.15, n.29, p.650-673, jul./dez. 2014. Disponível em: www.revistatopoi.org; Acesso em: 15 jul. 2015.

DARÓZ, Carlos. O Brasil na Primeira Guerra Mundial: a longa travessia. São Paulo: Contexto, 2016.

DEHNE, Phillip. How Important was Latin America to the First World War? Iberoamericana, v.XIV, n.53, p.151-164, 2014.

FULCHER, Jane F. French Cultural, Politics \& Music: From the Dreyfus Affair to the First World War. Oxford: Oxford University Press, 1999.

. The Composer as Intellectual: Music and Ideology in France 1914-1940. Oxford: Oxford University Press, 2005.

GARAMBONE, Sidney. A primeira Guerra Mundial e a imprensa brasileira. Rio de Janeiro: Mauad, 2003.

JIMÉNEZ, Patricia Veja. La guerra como espectáculo mediático: la prensa centroamericana en la Gran Guerra (1917). Historia y Comunicación Social, v.18, p.43-61, 2013.

KIEFER, Bruno. Villa-Lobos e o modernismo na música brasileira. 2.ed. Porto Alegre: Movimento; Brasília: INL; Fundação Nacional Pró-Memória, 1986.

LAGO, Manoel A. Corrêa do. O Círculo Veloso-Guerra e Darius Milhaud no Brasil: Modernismo musical no Rio de Janeiro antes da Semana. Rio de Janeiro: Reler, 2010.

(Org.) O boi no telhado: Darius Milhaud e música brasileira no modernismo francês. São Paulo: IMS (Instituto Moreira Salles), 2012.

MOLINA, Matias M. História dos jornais no Brasil. v.1 - Da era colonial à Regência (1500-1840). São Paulo: Companhia das Letras, 2015.

MILHAUD, Darius. An Autobiography: Notes without Music. New York: Alfred A. Knopf, 1953.

NOLAN, Michael. "The Eagle Soars over the Nightingale": Press and Propaganda in France in the Opening Months of the Great War. In: PADDOCK, Troy. A Call to Arms: Propaganda, Public Opinion, Newspapers in the Great War. Westport, CT: Praeger, 2004. p.51-90. 
NORONHA, Lina Maria R. de. Darius Milhaud: o nacionalismo francês e a conexão com o Brasil. Tese (Doutorado) - Programa de Pós-Graduação em Música, Instituto de Artes, Universidade Estadual Paulista "Júlio de Mesquita Filho" (Unesp). São Paulo, 2012.

OLIVEIRA, Thiago. A Liga da Defesa Nacional: um projeto de modernização para o Brasil. Dissertação (Mestrado) - Faculdade de Filosofia e Ciências (FFC), Universidade Estadual Paulista "Júlio de Mesquita Filho" (Unesp). Marília, 2012.

PADDOCK, Troy. World War I and Propaganda. Leiden \& Boston: Brill, 2014.

PEREIRA, Avelino R. Música, Sociedade e Política: Alberto Nepomuceno e a República Musical. Rio de Janeiro: Ed. UFRJ, 2007.

PERRIN, René Saint-Marie. Correspondance Claudel-Ruy Barbosa. Bulletin de la Société Paul Claudel, Paris, n.195, "Claudel et le Brésil", p.5-12, septembre 2009.

PIRES, Lívia C. Intelectuais nas trincheiras: a Liga Brasileira pelos Aliados e o debate sobre a Primeira Guerra Mundial (1914-1919). Dissertação (Mestrado) - Instituto de Filosofia e Ciências Humanas, Universidade do Estado do Rio de Janeiro (Uerj). Rio de Janeiro, 2013.

ROSHWALD, Aviel; STITES, Richard. European Culture in the Great War: The Arts, Entertainment, and Propaganda, 1914-1918. Cambridge: Cambridge University Press, 1999.

SCHMID, Marion. À bas Wagner! The French Press Campaign against Wagner during World War I. In: KELLY, Barbara L. (Org.) French music, culture and national identity, 1870-1939. Rochester, NY: University of Rochester Press, 2008. p.77-91.

SILVA, André Felipe C. Nas trincheiras do front intelectual: Henrique da Rocha Lima e a Primeira Guerra Mundial no Jornal do Commercio. Varia Historia, Belo Horizonte, v.31, n.57, p.635-671, set./dez. 2015.

SIRINELLI, Jean-François. As elites culturais. In: .; RIOUX, Jean-Pierre (Org.) Para uma história cultural. Lisboa: Ed. Estampa, 1998. p.259-279.

SPITZ, Clarice. Paul Claudel: le diplomate, la guerre et le Brésil. Bulletin de la Société Paulo Claudel, Paris, n.195, "Claudel et le Brésil", p.12-23, septembre 2009.

SISKIND, Mariano. The Spectacle of War at a Distance: Latin American Modernistas in World War I. MLN, v.1, n.2, (Hispanic Issue), p.234-255, mar. 2015.

STITES, Richard. Days and Nights in Wartime Russia: Cultural Life, 1914-1917. In: ROSHWALD, Aviel; . European Culture in the Great War: The Arts, Entertainment, and Propaganda, 1914-1918. Cambridge: Cambridge University Press, 1999. p.8-31.

TATO, María Inés. Nacionalismo e internacionalismo em la Argentina durante la Gran Guerra. Projeto História, São Paulo: PUC, n.36, p.49-62, jun. 2008.

. Luring Neutrals. Allied and German Propaganda in Argentina during the First World War. In: PADDOCK, Troy. World War I and Propaganda. Leiden \& Boston: Brill, 2014. p.322-351. 
VOLPE, Maria Alice. Indianismo and Landscape in the Brazilian Age of Progress: Art Music from Carlos Gomes to Villa-Lobos, 1870s-1930s. PhD Dissertation - The University of Texas. Austin, 2001.

WATKINS, Glenn. Proof Through the Night: Music and the Great War. Berkeley, CA: University of California Press, 2003.

\section{NOTAS}

${ }^{1}$ Este artigo faz parte de pesquisa de pós-doutorado desenvolvida na Fundação Casa de Rui Barbosa (FCRB) sobre os impactos culturais da Primeira Guerra Mundial no Brasil, sob supervisão do pesquisador Marcos Veneu.

${ }^{2}$ Fundada por Olavo Bilac em 7 de setembro de 1916, tinha como objetivo inserir os brasileiros nos debates sobre a questão nacional, possibilitando "a consolidação do Brasil para os brasileiros" (OLIVEIRA, 2012, p.14).

${ }^{3}$ A participação brasileira na Primeira Guerra Mundial, ao lado das forças aliadas, consistiu no envio da Missão Médico Militar Brasileira e da Divisão Naval de Operações em Guerra, cujo objetivo era patrulhar as águas do Attântico Sul. Contudo, dificuldades técnicas com a frota e a morte de parte de sua tripulação pela epidemia de gripe espanhola comprometeram a ação brasileira, que acabou pouco contribuindo para o fim do conflito (DARÓZ, 2016).

${ }^{4}$ Faço referência especificamente aos trabalhos de Sidney Garambone (GARAMBONE, 2003) sobre a imprensa carioca e à dissertação de Lívia Claro Pires (PIRES, 2013) sobre a Liga Brasileira pelos Aliados.

${ }^{5}$ Sobre as diversas fases da historiografia sobre a Primeira Guerra Mundial ver CORREIA, 2014.

6 “... um corpus de representações do conflito cristalizada em um verdadeiro sistema dando a guerra o seu significado profundo. Uma 'cultura' ... inseparável de uma manifestação espetacular de ódio contra o adversário" (AUDOIN-ROUZEAU; BECKER, 2000, p.145, trad. nossa).

${ }^{7}$ Muitos trabalhos têm procurado repensar essa relação, ressaltando sua importância tanto para as nações europeias, compreendidas em seu esforço de guerra, como para as nações americanas, compreendidas nos debates acirrados em prol, ou não, de sua inserção no conflito. Para trabalhar essa problemática, tomamos como base os trabalhos de SISKIND (2015), TATO (2008; 2014), JIMÉNEZ (2013), DEHNE (2014) e COMPAGNON (2014), que procuram enfatizar a importância do conflito nos debates nacionalistas perceptíveis nos anos da guerra e nas décadas de 1920 e 1930.

${ }^{8}$ Uma das primeiras atitudes dos aliados com relação à América Latina, no início da Primeira Guerra Mundial, foi cortar o cabo telegráfico submarino que estabelecia, desde 1909, comunicações entre a Alemanha e o continente latino (MOLINA, 2015). 
${ }^{9}$ Faço referência à série de Concertos Populares (1887-1893; 1897-1902) dirigida por Carlos Mesquita; aos Concertos Populares (1896-1897) de Alberto Nepomuceno; aos quatro Concertos Populares de Miguez (1900); aos Concertos Sinfônicos de Francisco Braga (1900-1901); e aos concertos sinfônicos do Clube dos Diários, dirigidos por Nepomuceno (1900-1901) (VOLPE, 2001).

${ }^{10}$ A Sociedade de Concertos Sinfônicos foi formada em 1912, por iniciativa de Francisco Braga e Francisco Nunes, e funcionou até a década de 1930.

${ }^{11}$ PIRES (2013) toma como referência a noção de "elite cultural" do historiador francês Jean-François Sirinelli (SIRINELLI, 1998, p.275), na qual ela é pensada essencialmente pelo seu poder de influência na sociedade, porém não como uma entidade autônoma à sociedade, pois também se define pela sua própria imagem que reflete a sociedade ao seu redor.

${ }^{12}$ Como já mencionado, o estudo mais completo, e quiçá único, sobre a Liga foi feito por Livia Pires, no qual nos baseamos para traçar suas principais características. Sobre a formação da Liga ver a primeira parte do segundo capítulo de sua dissertação (PIRES, 2013, p.57-66).

13 Segundo Lívia Claro Pires, a Liga Brasileira Pró-Germânia foi criada em junho de 1915, por iniciativa da colônia alemã no Rio de Janeiro (PIRES, 2013, p.30).

14 Carta de André Messager a Alberto Nepomuceno, 8 jan. 1917 (apud PEREIRA, 2007, p.346).

${ }^{15}$ Houve ainda um 20 Festival Debussy, em 17 de junho de 1918, como parte da série Hora Artística, realizada anualmente no Lycée Français.

16 Faço referência ao artigo que Darius Milhaud publicou na revista francesa Revue Musicale em 1920, no qual avaliava o cenário musical brasileiro. Sobre esse artigo, também publicado em abril de 1924 na revista paulista Ariel, ver LAGO $(2010 ; 2012)$.

Artigo recebido em 27 de junho de 2017. Aprovado em 26 de setembro de 2017. 